\title{
Intracranial Vessel Wall MRI: Principles and Expert Consensus Recommendations of the American Society of Neuroradiology
}

\author{
(DD.M. Mandell, (D) M. Mossa-Basha, (D)Y. Qiao, (DC.P. Hess, (D) F. Hui, (D) C. Matouk, (D) M.H. Johnson, (D) M.J.A.P. Daemen, \\ (D) A. Vossough, (D) M. Edjlali, (DD. Saloner, DS.A. Ansari, (DB.A. Wasserman, and DD.J. Mikulis, on behalf of the Vessel Wall Imaging \\ Study Group of the American Society of Neuroradiology
}

\begin{abstract}
SUMMARY: Intracranial vessel wall MR imaging is an adjunct to conventional angiographic imaging with CTA, MRA, or DSA. The technique has multiple potential uses in the context of ischemic stroke and intracranial hemorrhage. There remain gaps in our understanding of intracranial vessel wall MR imaging findings and research is ongoing, but the technique is already used on a clinical basis at many centers. This article, on behalf of the Vessel Wall Imaging Study Group of the American Society of Neuroradiology, provides expert consensus recommendations for current clinical practice.
\end{abstract}

ABBREVIATIONS: RCVS = reversible cerebral vasoconstriction syndrome; $V W-M R$ imaging = vessel wall MR imaging

C onventional techniques for imaging the intracranial arteries are CTA, MRA, and DSA. These techniques reveal abnormalities of the vessel lumen, but they can fail to fully characterize disease that resides within the vessel wall. There has been growing interest in direct visualization of the vessel wall with high-resolution intracranial vessel wall MR imaging (VW-MR imaging). This technique is now used on a clinical basis at many centers.

In 2012, the American Society of Neuroradiology formed a multidisciplinary study group to support the development and clinical implementation of VW-MR imaging. This article, on behalf of the study group, reviews the principles of intracranial VW-MR imaging and provides consensus recommendations for clinical practice. We make these recommendations with the rec-

From the Division of Neuroradiology (D.M.M., D.J.M.), Department of Medical Imaging, University Health Network and the University of Toronto, Toronto, Ontario, Canada; Department of Radiology (M.M.-B.), University of Washington, Seattle, Washington; The Russell H. Morgan Department of Radiology and Radiological Sciences (Y.Q., F.H., B.A.W.), Johns Hopkins Hospital, Baltimore, Maryland; Department of Radiology and Biomedical Imaging (C.P.H., D.S.), University of California, San Francisco, San Francisco, California; Departments of Neurosurgery (C.M., M.H.J.), Radiology and Biomedical Imaging (C.M., M.H.J.), and Surgery (M.H.J.), Yale University School of Medicine, New Haven, Connecticut; Department of Pathology (M.J.A.P.D.), Academic Medical Center, Amsterdam, the Netherlands; Departments of Surgery (A.V.) and Radiology (A.V.), Children's Hospital of Philadelphia and Perelman School of Medicine at the University of Pennsylvania, Philadelphia, Pennsylvania; Department of Radiology (M.E.), Université Paris Descartes Sorbonne Paris Cité, Institut National de la Santé et de la Recherche Médicale S894, Centre Hospitalier Sainte-Anne, Paris, France; and Departments of Radiology (S.A.A.), Neurology (S.A.A.), and Neurological Surgery (S.A.A.), Northwestern University, Feinberg School of Medicine, Chicago, Illinois.

Please address correspondence to Daniel Mandell, MD, Toronto Western Hospital, 399 Bathurst St, 3MCL-426, Toronto, ON, Canada, M5T 2S8; e-mail: danny.mandell@uhn.ca

- Indicates open access to non-subscribers at www.ajnr.org

http://dx.doi.org/10.3174/ajnr.A4893 ognition that there remain considerable gaps in knowledge and that research is ongoing.

\section{TECHNICAL IMPLEMENTATION}

The American Society of Neuroradiology Vessel Wall Imaging Study Group is working with MR imaging vendors to promote the development and dissemination of commercial pulse sequences that are optimized for intracranial VW-MR imaging. Until such sequences are widely available, it is possible to adjust the scan parameters of existing sequences and obtain vessel wall images of sufficient quality for clinical use. Selection of sequences and scan parameters for VW-MR imaging is highly dependent on the particular scanner hardware and software available at a center. The technical sections that follow provide general recommendations on the development of an intracranial VW-MR imaging protocol, and we are also launching a dynamic document (via the American Society of Neuroradiology Web site) through which experienced centers can describe their MR imaging systems and the specific pulse sequences and scan parameters that they have found useful.

The principal technical requirements for intracranial VW-MR imaging are the following: 1) high spatial resolution, 2) multiplanar $2 \mathrm{D}$ acquisitions or $3 \mathrm{D}$ acquisitions, 3 ) multiple tissue weightings, and 4) suppression of signal in luminal blood and CSF.

\section{Spatial Resolution}

The normal middle cerebral artery and basilar artery wall thickness is $0.2-0.3 \mathrm{~mm}$, which is approximately one-tenth of the luminal diameter ${ }^{1}$ and smaller than the VW-MR imaging voxel dimensions currently achievable. However, it is possible to image the intracranial arterial wall because the wall generates detectable MR imaging signal and one can suppress the MR imaging signal 


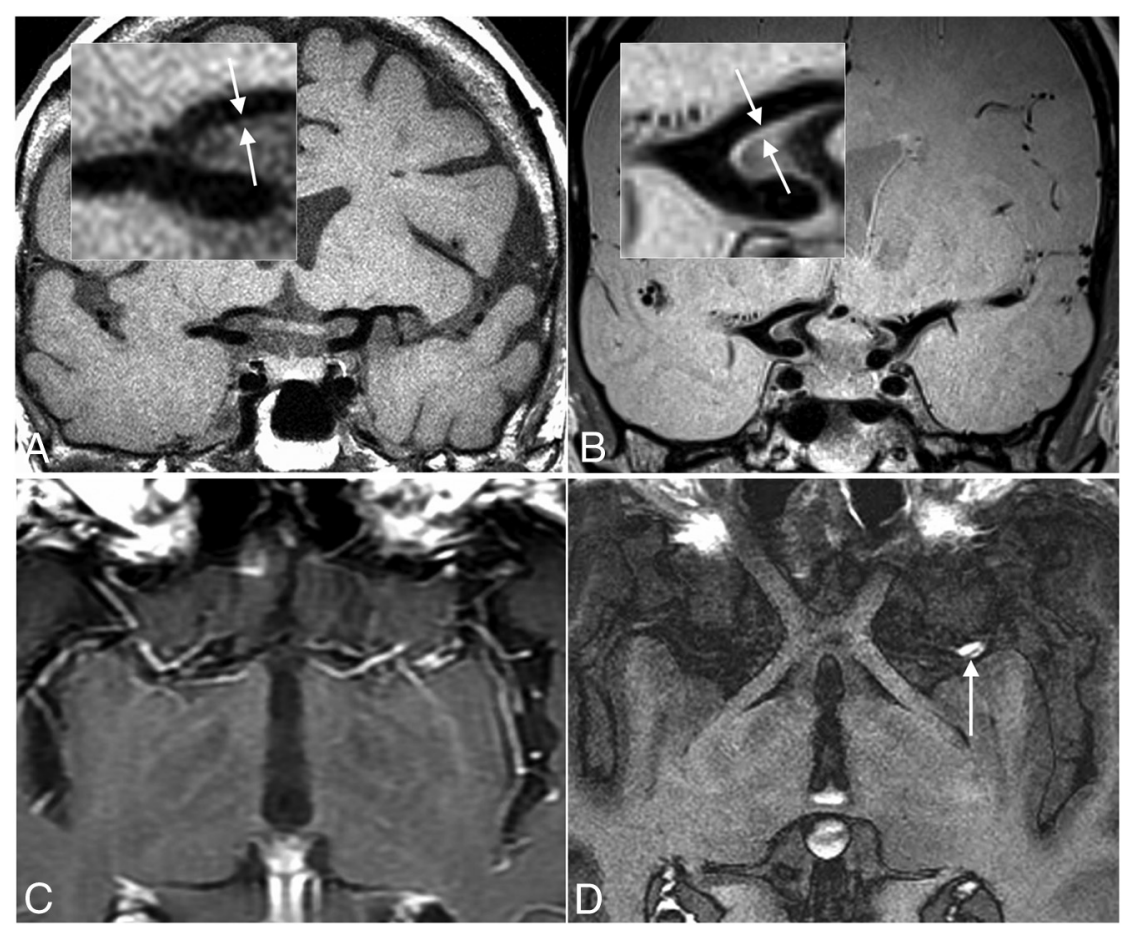

FIG 1. Technical implementation of VW-MR imaging. Comparison of a coronal 2D T1-weighted FLAIR VW-MR imaging sequence $(A)$ and a 3D proton-density-weighted variable flip angle refocusing pulse, fast spin-echo VW-MR imaging sequence $(B)$ in a healthy subject. Insets show magnified images of the carotid terminations with arrows pointing to the arterial wall. Comparison of a standard contrast-enhanced T1-weighted spin-echo sequence $(C)$ and an optimized contrast-enhanced Tl-weighted VW-MR imaging sequence $(D)$ shows how blood suppression is needed to reveal an enhancing atherosclerotic plaque (arrow) in the left MCA M1 segment.

planes. The 3D approach reduces total scan time and provides more flexibility because any imaged vessel can be viewed in any reformatted plane. However, some groups have found that current $2 \mathrm{D}$ sequences provide better image quality when imaging is targeted to a particular vessel of interest. An optimal VW-MR imaging protocol may include both $2 \mathrm{D}$ and $3 \mathrm{D}$ sequences.

\section{Multiple Tissue Weightings}

Time-of-flight MRA is mainly used to characterize luminal abnormality and act as a localizer for subsequent vessel wall sequences. Low-velocity flow can cause intravascular signal loss on time-of-flight MRA, so in patients who have pronounced luminal narrowing or dilation, it is helpful to add a gadolinium-bolus MRA to accurately define the contour of the lumen (ie, the boundary between the lumen and wall). Most examinations require a T1-weighted vessel wall sequence before and after intravenous gadolinium contrast. It is possible to use a protondensity-weighted sequence instead of a T1-weighted sequence because the former provides higher SNR. The disadvantages of proton-density weighting are that

arising from neighboring blood and CSF within the voxel. In addition, vessel wall disease often results in wall thickening, which increases its conspicuity.

The higher signal-to-noise ratio at $3 \mathrm{~T}$ than at $1.5 \mathrm{~T}$ is advantageous for intracranial VW-MR imaging and, in many cases, necessary. At $3 \mathrm{~T}$ with a $2 \mathrm{D}$ sequence, a voxel size of $2.0 \times 0.4 \times 0.4$ $\mathrm{mm}$ provides a reasonable balance between spatial resolution and signal-to-noise ratio, with a scan duration of approximately 5-7 minutes for a 2 - to 4 -cm-thick section of tissue (Fig 1A). At $3 \mathrm{~T}$ with a $3 \mathrm{D}$ sequence, a voxel size of $0.5 \mathrm{~mm}$ isotropic is a reasonable starting point (Fig 1B), and it is possible to cover the circle of Willis and second-/third-order branches in 7-10 minutes. Most experienced centers are using isotropic voxel dimensions in the 0.4 - to $0.7-\mathrm{mm}$ range for $3 \mathrm{D}$ acquisitions. Ongoing advances in MR imaging technology, including higher magnetic field strength, ${ }^{2}$ may enable further increases in spatial resolution and image quality. ${ }^{3}$

\section{Multiplanar 2D or 3D Acquisitions}

Accurate interpretation of $\mathrm{VW}-\mathrm{MR}$ imaging requires visualization of the vessel wall in both short- and long-axis planes. One option is to use $2 \mathrm{D}$ sequences multiple times in orthogonal planes, focusing on the particular vessels of interest. A limitation of this approach is that most intracranial arteries are curved rather than straight and vessel obliquity and curvature can result in partial volume averaging effects, ${ }^{4}$ which confound the appearance of the arterial wall. Another option is to use a 3D (volumetric) sequence and then reformat the isotropic data for viewing in multiple $2 \mathrm{D}$ contrast enhancement may be less conspicuous and CSF signal intensity can approach vessel wall intensity. A T2-weighted VW-MR imaging sequence is often helpful. Fat suppression is necessary for VW-MR imaging of the external carotid artery branches in the scalp (eg, in patients with suspected temporal arteritis) but is generally not needed for intracranial VW-MR imaging.

\section{Suppression of MR Imaging Signal in Blood and CSF}

MR imaging characterization of the vessel wall requires suppression of MR imaging signal arising from luminal blood and CSF (or brain parenchyma for a vessel residing adjacent to the brain) (Fig $1 C,-D)$. Blood-suppression techniques usually exploit the condition of blood flowing and the vessel wall being stationary. Other techniques for blood suppression rely on the particular longitudinal relaxation time (T1) of blood, but these techniques usually have some dependence on flow as well. The most common methods of blood-signal suppression are the following:

Spin-Echo. Luminal spins that experience the section-selective $90^{\circ}$ radiofrequency pulse but flow out of the imaging section before the section-selective $180^{\circ}$ pulse do not yield signal, resulting in blood-signal suppression. ${ }^{5}$

Spatial Presaturation (Saturation Band). A spatially selective pulse tips a thick slab of spins on either side of the imaging section into the transverse plane, and then a spoiling gradient dephases this transverse magnetization. ${ }^{5}$ The dephased spins flow into the imaging section, where they are exposed to an excitation pulse, but they 
are not able to regain phase in the transverse plane until they have undergone longitudinal relaxation, so they do not yield signal.

Double Inversion Recovery Preparation. This technique exploits both the flow and $\mathrm{T} 1$ properties of blood to suppress its signal. ${ }^{6} \mathrm{~A}$ $180^{\circ}$ non-section-selective pulse inverts all spins. A section-selective $180^{\circ}$ pulse, applied immediately after the first pulse, flips the imaging-section magnetization so it is realigned with the main magnetic field. There is then a time delay (TI), which allows inflowing inverted spins to relax to their null point; and at the expected null point for blood, another pulse is applied to generate an echo for readout. Only the stationary spins in the imaging section return signal. A disadvantage of the technique is that the time needed for spins to reach the null point lengthens the scan time, making it challenging to cover vessels of interest with sufficient spatial resolution for intracranial VW-MR imaging.

\section{D Sequences}

The most commonly used 3D sequences for intracranial VW-MR imaging are the variable flip angle refocusing pulse, fast spin-echo sequences $^{7}$ with brand names such as VISTA (volume isotropic turbo spin-echo acquisition; Philips Healthcare, Best, the Netherlands), SPACE (sampling perfection with application-optimized contrasts by using different flip angle evolutions; Siemens, Erlangen, Germany), and Cube (GE Healthcare, Milwaukee, Wisconsin). These sequences have very long echo trains, a potential source of imaging blurring from decay of transverse magnetization between the start and end of the readout. These sequences minimize this blurring by varying the flip angle over the length of the echo train to maintain relatively stable signal.

Blood suppression techniques used with 2D sequences are generally less effective with 3D sequences. For example, spatial presaturation requires that spins in the imaging volume are replaced with inflowing suppressed spins, but this is unlikely to occur for the entirety of a large 3D imaging slab. However, other mechanisms can generate adequate blood suppression with $3 \mathrm{D}$ sequences. An important mechanism is intravoxel dephasing: Luminal blood contains spins traveling at varying velocities (eg, due to laminar flow). Between the time of excitation and readout, these spins move through the magnetic field gradients at different rates, resulting in intravoxel phase dispersion with signal loss. ${ }^{8}$ One may further exploit the intravoxel dephasing effect by adding so-called diffusion-sensitizing gradient preparation to the $3 \mathrm{D}$ sequences. ${ }^{9,10}$ This approach is similar to diffusion-weighted imaging, but the b-values are orders of magnitude lower, so the sequence suppresses bulk flow rather than molecular diffusion. Several centers have reported the details of how they optimized commercially available 3D sequences for intracranial VW-MR imaging. ${ }^{11,12}$

\section{Peripheral Pulse Gating}

Most centers are currently performing intracranial VW-MR imaging without peripheral pulse gating. Pulse gating is potentially useful for VW-MR imaging of dilated intracranial arteries or large aneurysms in which gating to the point of maximum flow in the vessel may reduce the artifacts associated with slow flow and improve blood suppression.

\section{Monitored Versus Unmonitored}

When using 2D sequences, some groups monitor the examination and select the sequences and scan planes that will optimally show the vessels of interest. When using 3D sequences, monitoring is less critical but still sometimes helpful to determine coverage and select sequences.

\section{SITUATIONS IN WHICH INTRACRANIAL VW-MR IMAGING IS LIKELY A USEFUL ADJUNCT TO CONVENTIONAL IMAGING To Differentiate between Intracranial Atherosclerotic Plaque, Vasculitis, Reversible Cerebral Vasoconstriction Syndrome, Arterial Dissection, and Other Causes of Intracranial Arterial Narrowing}

Atherosclerotic Plaque. Atherosclerotic plaque is composed of lipids, thrombotic substances (platelets and fibrin), cellular material, and connective tissue matrix. Plaque progression is often associated with the development of a well-defined region of lipid accumulation ("lipid core") within the plaque, a fibromuscular layer ("fibrous cap") separating the lipid from the arterial lumen, and intraplaque hemorrhage. ${ }^{13-15}$

VW-MR imaging of intracranial atherosclerotic plaque typically demonstrates arterial wall thickening, which eccentrically (nonuniformly) involves the circumference of the arterial wall. The component of the plaque adjacent to the lumen is often hyperintense on T2-weighted images, and it may enhance (as discussed below), whereas the adjacent component is often hypointense on T2-weighted images and nonenhancing (Fig 2F). ${ }^{16-22}$ There is sometimes a third thin layer in the periphery of the plaque that enhances. This layered appearance of intracranial atherosclerotic plaque correlates with the VW-MR imaging appearance of carotid atherosclerotic plaque, and carotid endarterectomy specimens have shown that the enhancing layer adjacent to the lumen represents fibrous cap, the nonenhancing layer adjacent to this represents lipid core, and the peripheral thin rim of enhancement is due to increased vasa vasorum in the adventitia of the artery. ${ }^{23-25}$ Not every intracranial atherosclerotic plaque demonstrates all of these components on VW-MR imaging; for example, some plaques simply have the appearance of an eccentric homogeneously enhancing "lump" in the arterial wall. In addition, as we will discuss, not every intracranial plaque enhances.

The hypointensity-isointensity on T1- and T2-weighted images in the lipid core of atherosclerotic plaque differs from the MR imaging appearance of lipids in other tissues, such as subcutaneous fat, which is hyperintense on T1-weighted and T2-weighted fast spin-echo sequences. Two main factors likely account for this difference. First, even in relatively lipid-rich atherosclerotic plaque, the main contributor to MR signal is water protons and not lipid. ${ }^{23}$ Second, the lipid in atherosclerotic plaque is mainly cholesterol and cholesteryl esters, which do not result in the same T1 shortening as extravascular lipid, which is composed mainly of triglycerides. $^{26}$

Vasculitis. Visualization of the wall of the smaller intracranial vessels is beyond the spatial resolution and SNR limits of current VW-MR imaging. However, CNS vasculitis often involves larger intracranial arteries that are amenable to wall imaging. 


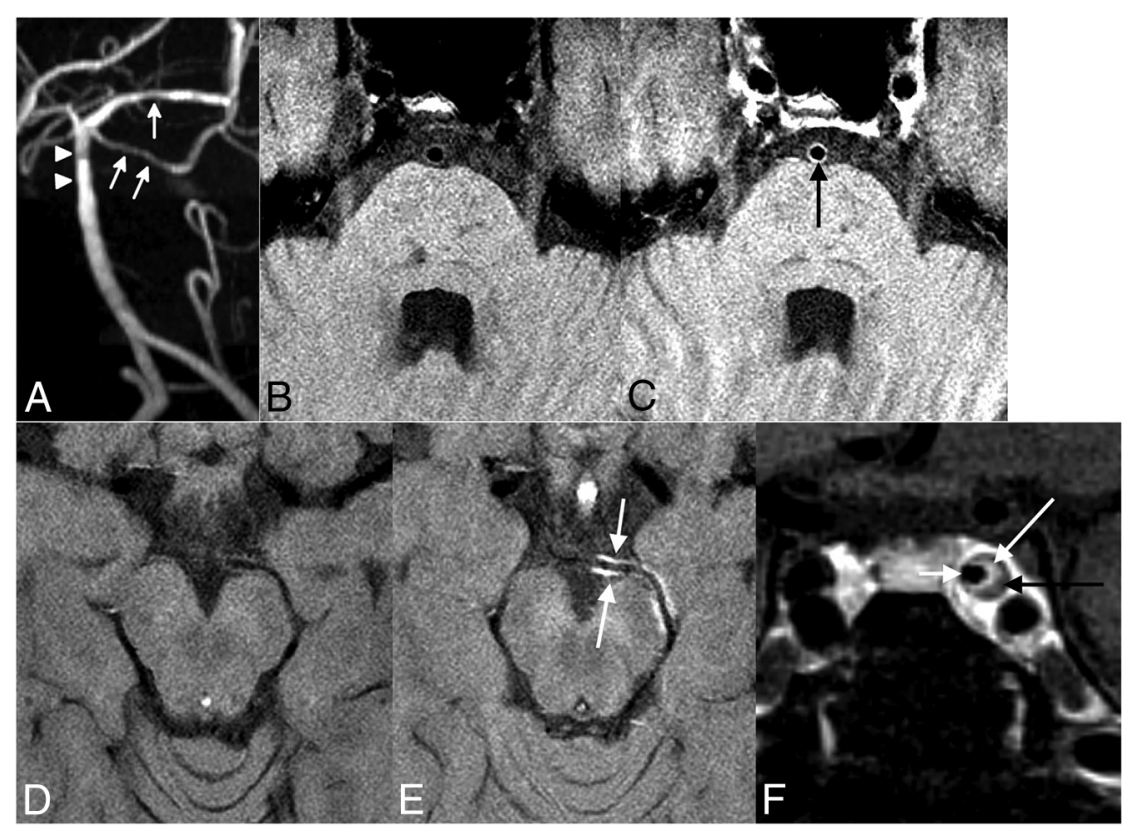

FIG 2. VW-MR imaging to differentiate among causes of intracranial arterial stenosis when angiography findings are inconclusive. This patient had multiple recent infarcts in the pons. MR angiogram $(A)$ demonstrates short segments of mild narrowing of the distal basilar artery (arrowheads) and left superior cerebellar and posterior cerebral arteries (arrows). Axial T1weighted VW-MR imaging before $(B)$ and after $(C)$ intravenous contrast injection shows smooth concentric enhancement of the basilar artery wall (arrow). VW-MR imaging before (D) and after (E) contrast injection shows similar enhancement of the left posterior cerebral artery wall (arrow). The vessel wall appearance is consistent with the final diagnosis, which was primary CNS vasculitis. For comparison, coronal contrast-enhanced T1-weighted VW-MR imaging $(F)$ in a different patient shows characteristic features of an atherosclerotic plaque: eccentric arterial wall thickening with a contrast-enhancing fibrous cap (long white arrow) and peripheral nonenhancing plaque (black arrow). A short white arrow points to the arterial lumen.

intense wall enhancement in active vasculitis. ${ }^{29,32,33}$ Arterial wall thickening with a lack of wall enhancement is consistent with the pathology of transient vasoconstriction. In vasospastic arteries, smoothmuscle cells shorten in length with increased overlap among cells, resulting in nearly a $500 \%$ increase in wall thickness for a $60 \%$ luminal narrowing. ${ }^{32,34}$ Lack of arterial wall enhancement is concordant with the limited histopathologic data in RCVS, showing an absence of arterial wall inflammation. ${ }^{32,35,36}$ We have seen some individual cases that appear to be RCVS with more than minimal wall enhancement, so we recommend caution in relying strongly on VW-MR imaging discrimination between RCVS and vasculitis until this approach is validated in a larger study. Some study group members have also observed a crenelated appearance of arterial wall thickening in RCVS.

Moyamoya Disease. Initial VW-MR imaging studies of small numbers of patients with Moyamoya disease found a lack of arterial wall thickening and enhancement ${ }^{19,37}$; and a study found a smaller outer diameter of the vessel wall, less eccentricity of wall thickening, and less wall enhancement in patients with Moyamoya disease compared with atherosclerotic

VW-MR imaging often demonstrates smooth, homogeneous, concentric arterial wall thickening and enhancement in patients with CNS vasculitis (Fig 2A-E), in comparison with the typical nonconcentric (and often heterogeneous) wall abnormality of atherosclerotic plaque (Fig 2F). ${ }^{19,27,28}$ However, subsequent experience has shown that vasculitis sometimes also results in eccentric wall abnormality. ${ }^{29}$ The additional vessel wall features of atherosclerotic plaque on T1-, T2-, and enhanced sequences can be helpful for distinguishing between vasculitis and plaque.

Presumably, arterial wall enhancement in patients with CNS vasculitis is due to increased permeability of the endothelium with contrast leakage from the lumen into the arterial wall. Vasa vasorum-related contrast leakage is a potential alternative mechanism of wall enhancement, and dilated neovessels have been demonstrated within the extracranial arterial wall of patients with Takayasu arteritis. ${ }^{30,31}$

Reversible Cerebral Vasoconstriction Syndrome. Early discrimination between reversible cerebral vasoconstriction syndrome (RCVS) and its principal differential, vasculitis, is important: RCVS is treated with observation or calcium channel blockers, whereas vasculitis is treated with steroids and immunosuppressive drugs.

VW-MR imaging may enable prospective differentiation between vasculitis and vasoconstriction. ${ }^{32}$ Both disorders result in arterial wall thickening, but the vessel wall in RCVS is typically nonenhancing (or mildly enhancing) compared with the typical plaque. ${ }^{38}$ Atherosclerotic plaque may undergo negative remodeling with reduction of the outer diameter of the vessel, but this seems to differ from Moyamoya disease, in which the MCA trunk is not visible at all in some cases, the so-called "vanishing MCA." 39 These VW-MR imaging findings are consistent with histopathologic studies showing thinning of the arterial media and a paucity of inflammatory cells in the vessel wall of patients with Moyamoya disease. ${ }^{40}$ However, a subsequent study ${ }^{41}$ found a considerably higher frequency of concentric internal carotid and middle cerebral artery wall enhancement in patients diagnosed with Moyamoya disease and, perhaps surprisingly, no difference in vessel wall enhancement between early and late angiographic stages of the disease. Further research is needed to resolve the discordance among studies. It will remain important to accurately differentiate between Moyamoya disease and the multitude of other causes of narrowing at the carotid terminus.

Radiation-Induced Arteriopathy. There is limited experience with the VW-MR imaging appearance of radiation-induced intracranial arteriopathy. A study ${ }^{37}$ of 5 patients with radiation-induced narrowing of the intracranial internal carotid arteries found circumferential arterial wall thickening and enhancement in all cases. Follow-up MR imaging 2 years later demonstrated persistence of the enhancement.

Arterial Dissection. Intracranial arterial dissection most often occurs as an extension of cervical vertebral artery dissection. How- 


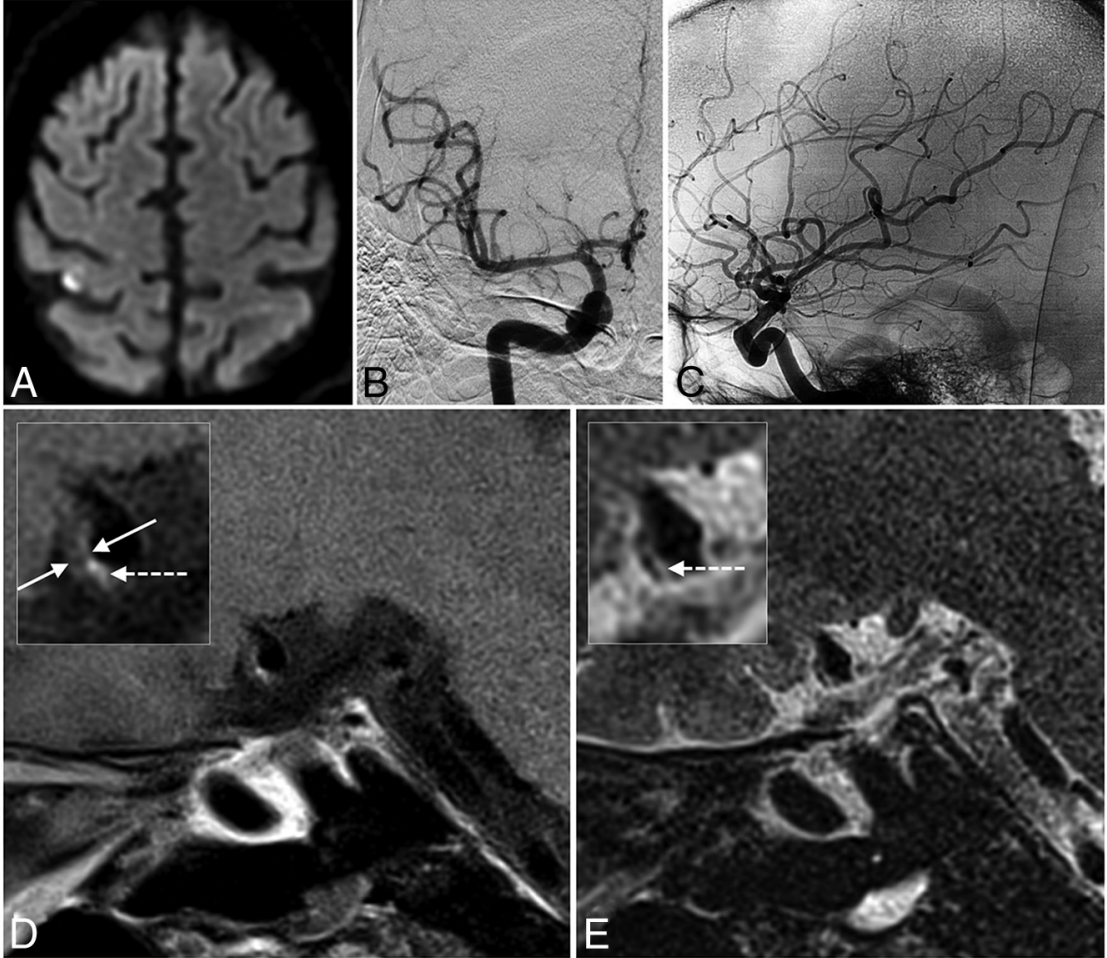

FIG 3. VW-MR imaging to identify symptomatic, nonstenotic intracranial atherosclerotic plaque. A 52-year-old man with a previous transient ischemic attack attributable to the right middle cerebral artery territory presented with an acute infarct $(A)$ in the same vascular territory. Cardiac work-up, CT angiography of the head and neck and DSA ( $B$ and $C$ ) and cervical carotid VW-MR imaging failed to identify a cause of the stroke. Sagittal-oblique contrastenhanced T1-weighted VW-MR imaging of the supraclinoid segment of the right ICA $(D)$ shows eccentric arterial wall thickening (arrows) with enhancement (dotted arrow) in the more luminal aspect of the thickening, consistent with the fibrous cap of a recently symptomatic plaque. Sagittal-oblique T2-weighted VW-MR imaging $(E)$ shows T2 prolongation (arrow) in the more luminal aspect of the thickening and T2 shortening peripherally, consistent with the fibrous cap and lipid core of atherosclerotic plaque, respectively. The arterial wall thickening without luminal narrowing is so-called positive remodeling of the vessel wall.

ever, it can also occur as an extension of cervical internal carotid artery dissection or as an isolated intracranial abnormality.

VW-MR imaging features of intracranial arterial dissection include a curvilinear hyperintensity on T2-weighted images (intimal flap) separating the true lumen from the false lumen and eccentric arterial wall thickening with the signal characteristics of blood (intramural hematoma) (Fig 3). ${ }^{42}$ A VW-MR imaging study ${ }^{43}$ of 67 patients with intracranial arterial dissection suspected on CTA, MRA, or DSA found an intimal flap on luminal imaging in $16 \%$ of patients and on VW-MR imaging in $42 \%$. VW-MR imaging demonstrated intramural hematoma in $61 \%$ of patients, with $83 \%$ of the visible hematomas evident on T1weighted images and 59\% evident on T2-weighted images. The vessel wall abnormality had a layered appearance on contrastenhanced T1-weighted images, with enhancement along the luminal and peripheral margins of the artery wall in $51 \%$ of patients.

Intramural hematoma is often diagnosed on the basis of hyperintensity on T1-weighted images, but similar to other kinds of intracranial hemorrhage, the signal characteristics of intramural blood evolve with time. ${ }^{44,45}$ Among 7 patients with intracranial vertebral-basilar dissection, no patient had vessel wall hyperintensity on T1-weighted VW-MR imaging within a week of symptom onset, but 5 patients had hyperintensity in a subsequent week. $^{46} \mathrm{~T}^{*}$-weighted or susceptibilityweighted MR imaging is also sometimes useful for the diagnosis of dissection. The deoxygenation of blood that makes it conspicuous on these sequences occurs earlier than the conversion from deoxyhemoglobin to methemoglobin required for intramural hematoma to become hyperintense on a T1-weighted sequence. ${ }^{47}$

The evolution of blood products is also complicated by the dynamic nature of dissection itself, which can be stable, progressive, or resolving. Intracranial arterial dissection with VW-MR imaging evidence of intramural hematoma is more likely to progress than dissection without hematoma. ${ }^{48}$

\section{To Identify Symptomatic, Nonstenotic Disease of the Intracranial Arteries}

In 15 patients with an acute lacunar infarct, normal angiography findings, and no other apparent cause of stroke, VW-MR imaging demonstrated enhancing atherosclerotic plaque in the supplying (middle cerebral or basilar) artery in 9 (60\%) patients. $^{49}$ Similar studies have shown VW-MR imaging evidence of atherosclerotic plaque in the supplying artery of $52 \%$ of patients with MCA territory lacunar infarcts and $42 \%$ of patients with pontine infarcts, but normal MRA findings. ${ }^{50,51} \mathrm{~A}$ VW-MR imaging study $y^{52}$ that assessed the prevalence of MCA plaque both ipsilateral and contralateral to lenticulostriate territory infarcts in patients who had normal MRA findings found a similar prevalence ( $46 \%$ and $45 \%$, respectively) bilaterally. This latter study did not report whether there was a difference in contrast enhancement between the plaques ipsilateral versus contralateral to the infarction. Figure 3 demonstrates VW-MR imaging identification of a culprit plaque when angiographic findings are normal. Study group members have also found that VW-MR imaging can help diagnose cases of CNS vasculitis and arterial dissection with minimal arterial luminal abnormality. Figure 4 demonstrates VW-MR imaging diagnosis of symptomatic intracranial arterial dissection in the context of a CTA considered equivocal for luminal narrowing.

\section{SITUATIONS IN WHICH INTRACRANIAL VW-MR IMAGING IS POSSIBLY A USEFUL ADJUNCT TO CONVENTIONAL IMAGING \\ To Determine the Location of Atherosclerotic Plaque Relative to Branch Artery Ostia, to Diagnose Stroke Etiology, and to Assess Risk of Angioplasty}

In the coronary circulation, atherosclerotic plaque most often develops in the arterial wall opposite a branch artery ostium. ${ }^{53} \mathrm{Sim}$ ilarly, intracranial VW-MR imaging has shown that MCA plaque 


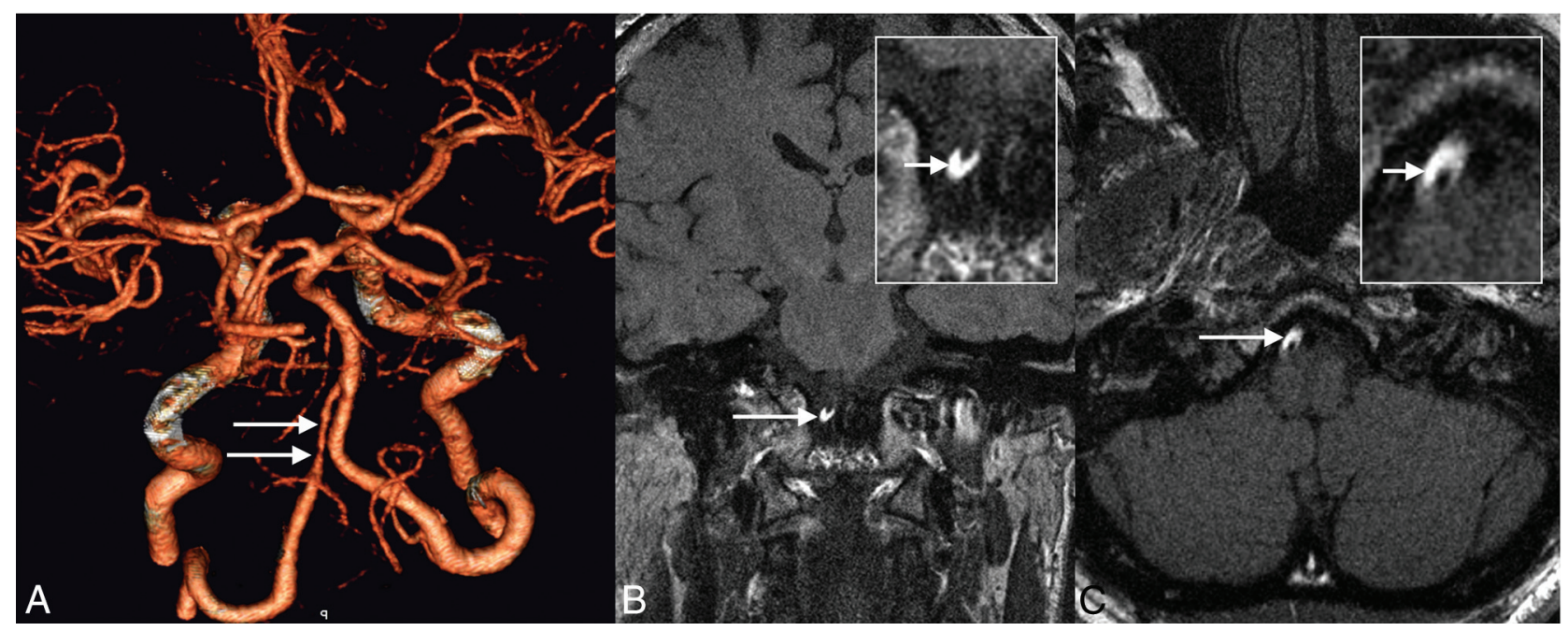

FIG 4. VW-MR imaging to diagnose intracranial arterial dissection with minimal luminal narrowing. A 57-year-old man presented to the emergency department with severe headache and neck pain for 1 week. 3D rendering of a CTA shows smooth narrowing of the intradural segment of the right vertebral artery (A, arrows). This angiographic appearance was considered most likely within the range of normal because the vertebral artery is commonly narrower beyond the posterior inferior cerebellar artery origin, but a bit equivocal. Coronal $(B)$ and axial $(C)$ nonenhanced T1-weighted VW-MR imaging shows eccentric intense hyperintensity ( $B$ and $C$, arrows) in the wall of the right vertebral artery, consistent with recent arterial dissection.

is more common in the ventral (45\%) or inferior $(32 \%)$ parts of the wall than in the superior (14\%) or dorsal (9\%) parts where branches arise, ${ }^{54,55}$ and basilar artery plaque is more common in the ventral part of the wall, which is opposite the origins of the branches. ${ }^{56}$ However, some atherosclerotic plaque does arise close to ostia, and VW-MR imaging has confirmed that indeed MCA plaque with associated infarction has more superior wall involvement than plaque without infarction (24\% versus $7 \%){ }^{54}$

Angioplasty can generate a "snow plow" effect, in which atheromatous material is pushed from the treated artery into a branch. In the coronary circulation, location of atherosclerotic plaque close to a branch ostium increases the risk of branch occlusion following angioplasty and stent placement. ${ }^{57}$ By determining the location of intracranial atherosclerotic plaque relative to branch ostia in individual patients, VW-MR imaging may be useful when estimating the risk of intracranial angioplasty. ${ }^{58}$

\section{To Assess Atherosclerotic Plaque Activity}

Higher risk intracranial atherosclerotic plaque shares pathologic features with higher risk carotid plaque. ${ }^{59}$ Several imaging features may indicate higher-risk plaque.

Plaque Thickness and Surface Irregularity. Most VW-MR imaging studies ${ }^{20,21}$ suggest that symptomatic intracranial plaque is thicker than asymptomatic plaque, though some ${ }^{60}$ have found no significant relationship. A study of 14 patients with symptomatic MCA stenosis and 16 patients with asymptomatic stenosis found plaque surface irregularity (discontinuity of the plaque luminal surface margin) in $71 \%$ of symptomatic patients but in only $19 \%$ of asymptomatic patients $(P=.008) .{ }^{61}$

Vessel Wall Remodeling. Atherosclerotic plaque often results in outward bulging of the outer surface of the artery. ${ }^{62}$ This has been called compensatory enlargement ("adaptive remodeling" or "positive remodeling") because it can lessen the luminal narrowing caused by the plaque. In the coronary arteries, positive remod- eling is more common in plaques that contain hemorrhage and inflammation ${ }^{63}$; this feature suggests that positive remodeling is an indicator of higher risk vessel wall pathology. Other plaques are associated with reduction of the outer diameter of the artery ("negative remodeling"), ${ }^{64}$ and this may reflect a fibrotic healing response. Most VW-MR imaging studies ${ }^{20,61}$ have found that MCA remodeling was (on average) outward in symptomatic plaques and inward in asymptomatic plaques, though some studies ${ }^{16}$ have found no significant difference. Microembolic signals on transcranial Doppler sonography were more common in patients with MCA atherosclerotic plaque with VW-MR imaging evidence of positive remodeling, ${ }^{65}$ consistent with the idea that positive remodeling is characteristic of the higher risk plaque that produces thromboembolism.

Intraplaque Hemorrhage. A postmortem study of MCA atherosclerosis found intraplaque hemorrhage in $30 \%$ of plaques associated with an infarct compared with $15 \%$ of plaques not associated with an infarct $(P=.07) .{ }^{66} \mathrm{~A}$ VW-MR imaging study of 107 adults with $>70 \%$ MCA stenosis found that $\mathrm{T} 1$ shortening (thought to indicate intraplaque hemorrhage) was more common in symptomatic than in asymptomatic plaque $(20 \%$ versus $2 \%$, $P=.01) .{ }^{66}$ Another study reported a higher prevalence of intraplaque T1 shortening in symptomatic-versus-asymptomatic MCA plaques (27\% versus $0 \%, P=.002) .{ }^{60} \mathrm{In}$ a research context, a signal intensity of $>150 \%$ of the signal intensity of adjacent gray matter $^{60}$ or scalp muscle ${ }^{66}$ on a T1-weighted sequence has been used as a criterion for defining intraplaque hemorrhage. Several study group members have observed a much lower prevalence of intracranial intraplaque hemorrhage than the values reported in the literature, possibly due to different patient populations or timing of the scans relative to symptom onset.

Plaque Enhancement. Contrast enhancement of carotid bulb atherosclerotic plaque occurs preferentially in the fibrous cap and 

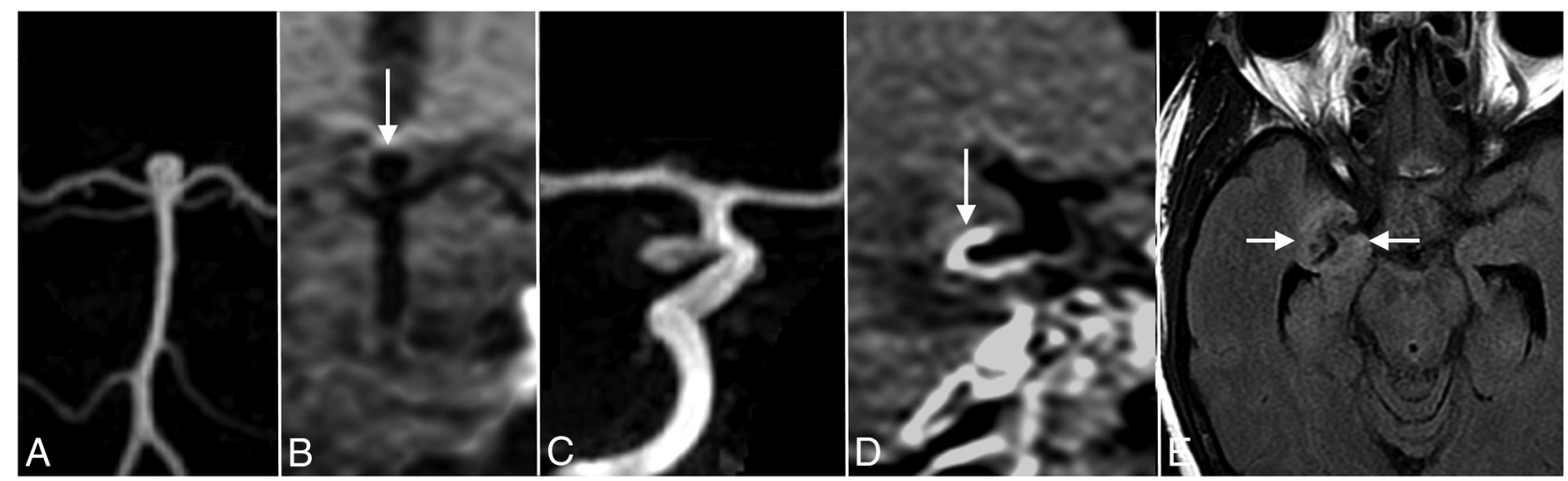

FIG 5. VW-MR imaging to evaluate vascular disease activity. MR angiogram demonstrates a saccular aneurysm at the tip of the basilar artery $(A)$ and a saccular aneurysm at the right posterior communicating artery origin (C). Coronal contrast-enhanced TT-weighted VW-MR imaging shows no enhancement of the basilar artery aneurysm wall $(B$, arrow) but intense enhancement of the posterior communicating artery aneurysm wall ( $D$, arrow). Axial T2-weighted FLAIR image ( $E$, arrow) demonstrates a hematoma centered around the enhancing aneurysm, consistent with the preliminary research studies, suggesting that symptomatic and ruptured aneurysms have wall enhancement much more commonly than asymptomatic saccular aneurysms.

adventitia (though sometimes in the middle of the plaque) and is a marker of inflammation and neovascularization. ${ }^{25,67-69}$ A postmortem study ${ }^{59}$ found that neovascularity in MCA atherosclerotic plaque was associated with ipsilateral infarction. VW-MR imaging studies ${ }^{19,70,71}$ have shown that intracranial plaque enhancement is associated with recent infarction in the territory of the plaque.

A study of the temporal characteristics of intracranial plaque enhancement found strong enhancement within 1 month of ischemic stroke and reduced enhancement several months later. ${ }^{72}$ Another study ${ }^{73}$ found no difference in enhancement when comparing patients with acute stroke versus those with stroke any time in the preceding 3 months, which is not inconsistent with the former study, which found that enhancement did not lessen until a few months after the acute event.

In some intracranial plaques, one can identify the enhancing fibrous cap and enhancing adventitia as distinct layers on either side of an intervening nonenhancing layer, but (possibly due to the limited spatial resolution of VW-MR imaging relative to the size of intracranial plaques) plaques often appear to enhance diffusely or not at all.

\section{To Assess Vasculitis Activity}

A small number of published cases ${ }^{29}$ and the broader experience of the study group suggest that there may be a discordance between intracranial VW-MR imaging findings and the clinical impression of vasculitis disease activity. This is consistent with extracranial VW-MR imaging observations. An extracranial VW-MR imaging study of 24 patients with Takayasu arteritis found arterial wall edema (hyperintensity on T2-weighted images) in 94\% of VW-MR imaging examinations performed in patients with clinically active disease and in $56 \%$ of examinations performed in those without clinically active disease. ${ }^{74}$ There was also greater wall enhancement in those with clinically active disease. The high prevalence of wall edema in patients without clinically active disease may not be misleading though: In a different study, biopsy specimens revealed histopathologic evidence of active vasculitis in $44 \%$ of patients with Takayasu arteritis who had no clinical evidence of active disease. ${ }^{75}$ Similarly, a study found new stenotic lesions on serial angiography in $61 \%$ of patients who were in clinical remission. $^{76}$
The effects of treatment on inflammatory VW-MR imaging findings are potentially important. Intracranial VW-MR imaging data are lacking, but the sensitivity of extracranial VW-MR imaging for the diagnosis of temporal arteritis was lower in patients who were imaged $>2$ days after starting corticosteroid treatment. ${ }^{77}$

\section{To Select an Intracranial Target for Biopsy in Suspected CNS Vasculitis}

Extracranial VW-MR imaging has been used to identify an inflamed segment of the superficial temporal artery and guide arterial biopsy to diagnose giant cell arteritis. ${ }^{78}$ There is a lack of high-quality data on the sensitivity and specificity of brain (or leptomeningeal) biopsy for the diagnosis of CNS vasculitis. However, CNS vasculitis can be spatially heterogeneous, and falsenegative biopsies occur. Study group members have found that VW-MR imaging is a potential means of identifying a peripherally located inflamed vessel to target for biopsy.

\section{To Determine Which Aneurysm Has Ruptured in Patients with Acute Subarachnoid Hemorrhage and Multiple Aneurysms}

There has been more experience with intracranial VW-MR imaging in the context of ischemic stroke than subarachnoid hemorrhage. However, preliminary results suggest that VW-MR imaging may be a useful technique for evaluating patients with intracranial aneurysms. An initial study ${ }^{79}$ used a 2D double inversion recovery VW-MR imaging sequence at $1.5 \mathrm{~T}$ with a voxel size of $0.5 \times 0.6 \times 0.3 \mathrm{~mm}$ to image the wall of saccular aneurysms, and there have been subsequent studies of the berry aneurysm wall at $3 \mathrm{~T}$ and $7 \mathrm{~T} .{ }^{80}$

A VW-MR imaging study ${ }^{81}$ of 5 patients with aneurysmal subarachnoid hemorrhage found that all ruptured aneurysms demonstrated thick peripheral enhancement. Three patients in this series had multiple aneurysms, and the unruptured aneurysms did not enhance. A subsequent study ${ }^{82}$ confirmed these findings in a larger sample size: There was aneurysm wall enhancement in $16 / 17$ ruptured aneurysms; enhancement in 5/5 unruptured aneurysms that had changed in morphology compared with a previous angiogram; and enhancement in 6/9 symptomatic unruptured aneurysms; but wall enhancement in only 22/77 unrup- 


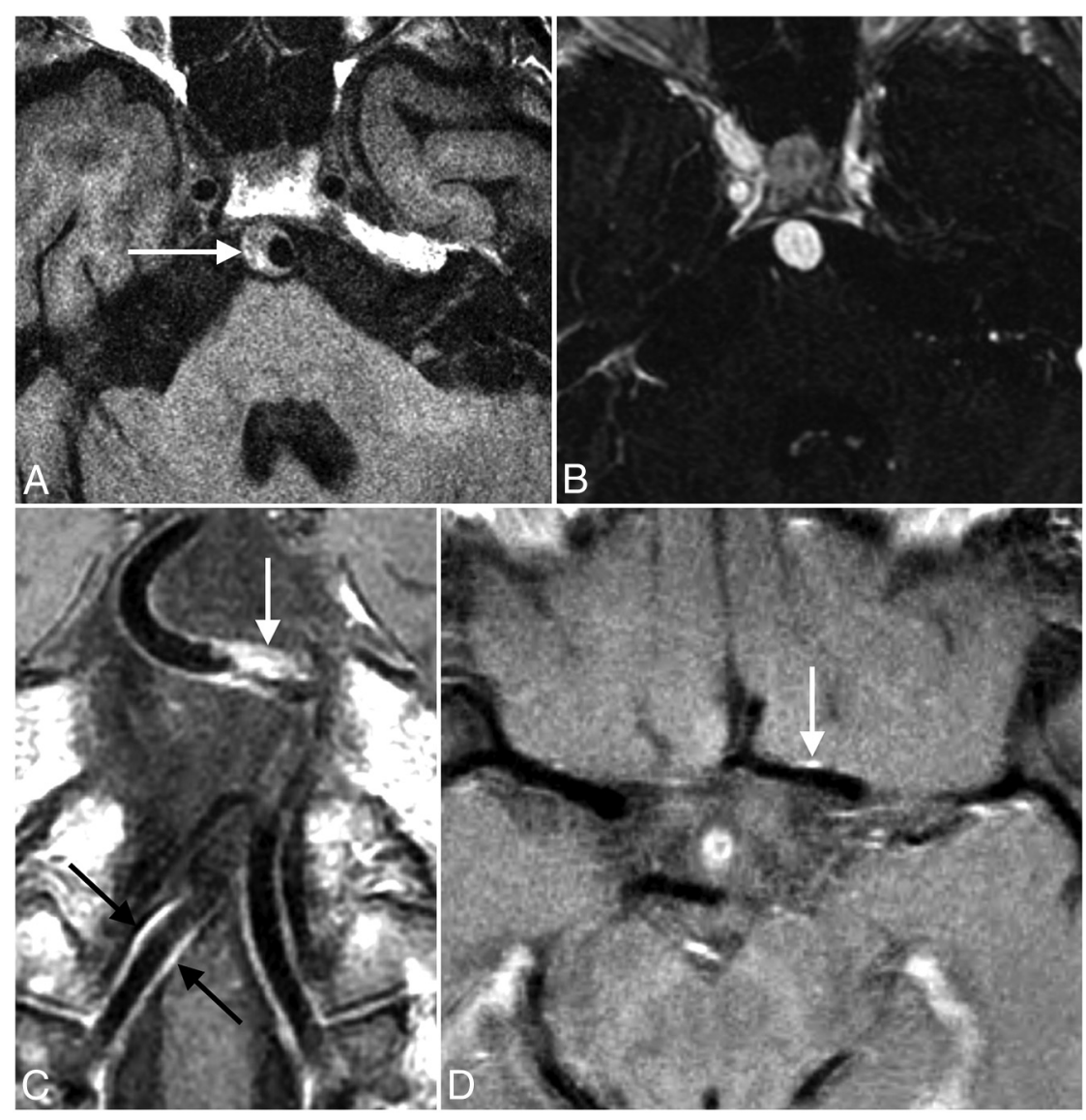

FIG 6. Common VW-MR imaging pitfalls. Case $1(A$ and $B)$ shows how slow flow can mimic arterial wall disease. Axial nonenhanced T1-weighted VW-MR imaging $(A)$ demonstrates a crescent (arrow) of intermediate-to-hyperintense signal at the periphery of the basilar artery, suggestive of arterial wall thickening from dissection or atherosclerotic plaque. A corresponding image from a gadolinium-enhanced MRA $(B)$ shows that the crescent of apparent arterial wall thickening fills with contrast and therefore represents a dilated basilar artery lumen rather than the arterial wall. Case $2(C)$ shows how vasa vasorum can mimic vasculitis. Coronal contrast-enhanced T1-weighted VW-MR imaging shows a focal atherosclerotic plaque (white arrow) of the basilar artery, but also more diffuse smooth concentric enhancement of the vertebral (black arrows) and basilar artery walls, which has an appearance similar to that of vasculitis. The diffuse enhancement is consistent with increased intracranial vasa vasorum in this patient who has strong atherosclerotic risk factors. Case $3(D)$ shows how a normal vein residing close to an artery can mimic arterial wall disease, such as enhancing atherosclerotic plaque. Axial contrast-enhanced Tl-weighted VW-MR imaging shows a vein (arrow) adjacent to the left middle cerebral artery.

aneurysms. $^{84,85}$ These inflammatory changes were already present shortly after the rupture and were not more pronounced when there was greater time between aneurysm rupture and surgical excision, suggesting that aneurysm wall inflammation might precede rupture rather than occur as a result of rupture. ${ }^{84}$ If aneurysm wall inflammation is an important factor in aneurysm growth and rupture, then vessel wall enhancement may be a marker of rupture risk. However, prospective longitudinal studies are needed to prove that this is correct.

There is also interest in measuring aneurysm wall thickness to predict rupture risk. However, berry aneurysm wall thickness is approximately $0.02-0.5 \mathrm{~mm},{ }^{86}$ leading to overestimation of wall thickness from the partial volume effects that will occur at the spatial resolutions currently achievable. ${ }^{87}$ It is not yet possible to accurately measure berry aneurysm wall thickness by using VW-MR imaging.

\section{IMPORTANT PITFALLS}

Accurate diagnosis by using VW-MR imaging is critically dependent on both an adequate imaging technique and interpretive experience. When either of these is lacking, normal variations are easily misinterpreted as disease.

\section{Slow Flow}

Most VW-MR imaging techniques rely on blood flow to achieve blood-signal suppression. Blood flow is often laminar, with lower velocity closer to the vessel wall. Incomplete signal suppression in the periphery of the lumen can mimic vessel wall thickening and/or wall enhancement (Fig 6A, -B). Factors predisposing to these artifacts include

tured, asymptomatic, stable aneurysms. Another study ${ }^{10}$ had similar results. Figure 5 provides an example of VW-MR imaging in a patient with 2 aneurysms, 1 unruptured and 1 ruptured.

There has also been interest in using VW-MR imaging to determine the source of hemorrhage in patients with angiogramnegative non-perimesencephalic subarachnoid hemorrhage, ${ }^{83}$ but no evidence yet of utility.

\section{SITUATIONS IN WHICH INTRACRANIAL VW-MR IMAGING IS CURRENTLY IN THE DOMAIN OF RESEARCH}

\section{To Predict Future Behavior of Unruptured Intracranial Saccular Aneurysms}

A study of human aneurysm tissue found diffuse invasion of macrophages and leukocytes into the vessel wall of ruptured aneurysms but few inflammatory cells in the wall of unruptured recirculating or slow flow within an aneurysm, low velocity flow in a dilated artery, and retrograde filling of a branch artery via leptomeningeal collaterals when there is proximal arterial occlusion. ${ }^{88}$

\section{Vasa Vasorum}

The walls of major extracranial arteries receive blood supply through the vasa vasorum, a network of small vessels within the outer aspect of the vessel wall itself. Intracranial vessels in children lack a vasa vasorum. ${ }^{89}$ However, with increasing age and with atherosclerotic risk factors, extracranial vasa vasorum can extend into the proximal intracranial segments of the internal carotid and vertebral arteries. ${ }^{90}$ In patients with a variety of intracranial arterial diseases, a vasa vasorum can also develop distant from the extracranial vasa vasorum, with supply from nearby intracranial arteries. ${ }^{91}$ A vasa vasorum can cause concentric arterial wall thickening and enhancement, ${ }^{92}$ which mimic vasculitis (Fig 6C). 


\section{Veins}

An enhancing vein located adjacent to an artery can mimic arterial wall enhancement (Fig 6D). It is usually possible to avoid this by careful examination of VW-MR imaging in multiple planes and comparison with MR angiography.

\section{Effects of Thromboembolism and Thrombectomy on the Arterial Wall}

Does thromboembolism itself injure the arterial wall and change the appearance of the wall? Does mechanical thrombectomy alter the appearance of the wall? These issues were explored in a VW-MR imaging study of 16 patients imaged within days of acute intracranial arterial occlusion. ${ }^{93}$ The cause of stroke was an extracranial source of thromboembolism in most cases, and the intracranial arteries had fully recanalized at the time of VW-MR imaging in most cases. The study found that mechanical thrombectomy results in concentric intracranial arterial wall thickening and enhancement, potentially mimicking the VW-MR imaging appearance of primary arteritis. A similar arterial wall abnormality was observed in patients treated with medical therapy alone, but it was less common in this group.

\section{RECOMMENDATIONS FOR CLINICAL PRACTICE Intracranial VW-MR Imaging Is Likely a Useful Adjunct to Conventional Imaging}

1) To differentiate among causes of intracranial arterial narrowing such as intracranial atherosclerotic plaque, vasculitis, reversible cerebral vasoconstriction syndrome, and arterial dissection.

2) To identify symptomatic, nonstenotic disease of the intracranial arteries.

\section{Intracranial VW-MR Imaging Is Possibly a Useful Adjunct to Conventional Imaging}

1) To determine the location of atherosclerotic plaque relative to branch artery ostia.

2) To assess atherosclerotic plaque activity.

3) To assess vasculitis activity.

4) To select an intracranial target for biopsy in suspected CNS vasculitis.

5) To determine which aneurysm has ruptured in patients with acute subarachnoid hemorrhage and multiple aneurysms.

\section{Intracranial VW-MR Imaging Is Currently in the Domain of Research}

1) To predict future behavior of unruptured intracranial saccular aneurysms.

\section{Technical Implementation}

1) Use pulse sequences that provide sufficient spatial resolution, black blood, and preferably black CSF.

2) Use $2 D$ sequences in short- and long-axis planes through the vessels of interest, and/or 3D sequences with isotropic voxel dimensions and multiplanar reformatting.

3) Modify the VW-MR protocol in response to the particular clinical indication. Protocols will often include a time-of-flight MRA of the circle of Willis, T1-weighted (or proton-density- weighted) vessel wall sequences before and after intravenous administration of gadolinium, and T2-weighted sequences. Consider adding a gadolinium-bolus MRA, particularly if there is severe arterial narrowing or arterial dilation.

4) Recognize that the true performance capabilities of MR images are often unclear and important characteristics such as spatial resolution depend on multiple factors and not simply voxel size. Therefore, quantitative measurements (such as vessel wall thickness) should be validated against calibration standards by using phantom testing.

\section{Interpretation}

1) Interpret $\mathrm{VW}-\mathrm{MR}$ imaging using the fundamental principles of radiologic interpretation used in other body tissues. Confirm vessel wall findings in multiple planes and preferably with multiple tissue weightings, and combine information from all available sequences to determine whether there is vessel wall thickening or enhancement. This assessment requires accurate determination of the inner and outer boundaries of the vessel wall by direct comparison of T1-, T2-, and contrast-enhanced T1weighted images and MRA source images. For accurate interpretation, it is critical to harmonize observed abnormalities across all sequences.

2) Recognize common pitfalls such as age-related vasa vasorum enhancement in the large intracranial arteries near the skull base, slow flow mimicking arterial wall thickening or enhancement, normally enhancing veins that are commonly seen close to arteries, and the effects of therapy on the vessel wall.

3) Always seek knowledge of the broader clinical context of the VW-MR imaging.

4) Communicate VW-MR imaging results to referring physicians along with the appreciation that certain VW-MR imaging findings are well-studied but others (which may still be important) are not yet fully validated.

\section{ACKNOWLEDGMENTS}

The authors thank Dr. Max Wintermark and the Executive Committee of the ASNR for constructive feedback on our draft manuscript.

Disclosures: Christopher P. Hess-UNRELATED: Expert Testimony: various legal firms (medical-legal consulting); Grants/Grants Pending: National Institutes of Health,* Quest Diagnostics, ${ }^{*}$ Cerebrotech Medical*; Payment for Lectures (including service on Speakers Bureaus): Siemens, ${ }^{\star}$ Comments: travel and lodging to lecture on neuroimaging for internal research and development at Siemens Healthcare. David Saloner-UNRELATED: Grants/Grants Pending: National Institutes of Health. * Sameer A. Ansari-UNRELATED: Grants/Grants Pending: American Heart Association, ${ }^{*} \mathrm{Na}$ tional Institutes of Health.* Bruce A. Wasserman-Patents (planned, pending or issued): Dr Wasserman has a patent pending (No. 13/922,111) for a 3D black-blood MR imaging technique mentioned in this article; however, there have been no license agreements and he has not received any payments related to his patent application. *Money paid to the institution.

\section{REFERENCES}

1. Gutierrez J, Elkind MS, Petito C, et al. The contribution of HIV infection to intracranial arterial remodeling: a pilot study. Neuropathology 2013;33:256-63 CrossRef Medline

2. van der Kolk AG, Hendrikse J, Brundel M, et al. Multi-sequence whole-brain intracranial vessel wall imaging at 7.0 Tesla. Eur Radiol 2013;23:2996-3004 CrossRef Medline

3. Zhu $\mathrm{C}$, Haraldsson $\mathrm{H}$, Tian $\mathrm{B}$, et al. High resolution imaging of the 
intracranial vessel wall at 3 and $7 \mathrm{~T}$ using 3D fast spin echo MRI. Magma 2016;29:559-70 CrossRef Medline

4. Antiga L, Wasserman BA, Steinman DA. On the overestimation of early wall thickening at the carotid bulb by black blood MRI, with implications for coronary and vulnerable plaque imaging. Magn Reson Med 2008;60:1020-28 CrossRef Medline

5. Edelman RR, Mattle HP, Wallner B, et al. Extracranial carotid arteries: evaluation with "black blood" MR angiography. Radiology 1990;177:45-50 CrossRef Medline

6. Edelman RR, Chien D, Kim D. Fast selective black blood MR imaging. Radiology 1991;181:655-60 CrossRef Medline

7. Busse RF, Hariharan $\mathrm{H}, \mathrm{Vu} \mathrm{A}$, et al. Fast spin echo sequences with very long echo trains: design of variable refocusing flip angle schedules and generation of clinical T2 contrast. Magn Reson Med 2006; 55:1030-37 CrossRef Medline

8. Alexander AL, Buswell HR, Sun Y, et al. Intracranial black-blood MR angiography with high-resolution 3D fast spin echo. Magn Reson Med 1998;40:298-310 CrossRef Medline

9. Fan Z, Zhang Z, Chung YC, et al. Carotid arterial wall MRI at $3 T$ using 3D variable-flip-angle turbo spin-echo (TSE) with flow-sensitive dephasing (FSD). J Magn Reson Imaging 2010;31:645-54 CrossRef Medline

10. Nagahata $S$, Nagahata $M$, Obara $M$, et al. Wall enhancement of the intracranial aneurysms revealed by magnetic resonance vessel wall imaging using three-dimensional turbo spin-echo sequence with motion-sensitized driven-equilibrium: a sign of ruptured aneurysm? Clin Neuroradiol 2014 Oct 21. [Epub ahead of print] Medline

11. Qiao Y, Steinman DA, Qin Q, et al. Intracranial arterial wall imaging using three-dimensional high isotropic resolution black blood MRI at 3.0 Tesla. J Magn Reson Imaging 2011;34:22-30 CrossRef Medline

12. Zhang L, Zhang $\mathrm{N}, \mathrm{Wu}$ J, et al. High resolution three dimensional intracranial arterial wall imaging at $3 \mathrm{~T}$ using $\mathrm{T} 1$ weighted SPACE. Magn Reson Imaging 2015;33:1026-34 CrossRef Medline

13. Fuster V, Moreno PR, Fayad ZA, et al. Atherothrombosis and highrisk plaque: part I, evolving concepts. J Am Coll Cardiol 2005;46: 937-54 CrossRef Medline

14. Virmani R, Kolodgie FD, Burke AP, et al. Lessons from sudden coronary death: a comprehensive morphological classification scheme for atherosclerotic lesions. Arterioscler Thromb Vasc Biol 2000;20: 1262-75 CrossRef Medline

15. Stary HC, Chandler AB, Dinsmore RE, et al. A definition of advanced types of atherosclerotic lesions and a histological classification of atherosclerosis: a report from the Committee on Vascular Lesions of the Council on Arteriosclerosis, American Heart Association. Arterioscler Thromb Vasc Biol 1995;15:1512-31 CrossRef Medline

16. Lam WW, Wong KS, So NM, et al. Plaque volume measurement by magnetic resonance imaging as an index of remodeling of middle cerebral artery: correlation with transcranial color Doppler and magnetic resonance angiography. Cerebrovasc Dis 2004;17:166-69 Medline

17. Klein IF, Lavallée PC, Schouman-Claeys E, et al. High-resolution MRI identifies basilar artery plaques in paramedian pontine infarct. Neurology 2005;64:551-52 CrossRef Medline

18. Klein IF, Lavallée PC, Touboul PJ, et al. In vivo middle cerebral artery plaque imaging by high-resolution MRI. Neurology 2006;67: 327-29 CrossRef Medline

19. Swartz RH, Bhuta SS, Farb RI, et al. Intracranial arterial wall imaging using high-resolution 3-Tesla contrast-enhanced MRI. Neurology 2009;72:627-34 CrossRef Medline

20. Xu WH, Li ML, Gao S, et al. In vivo high-resolution MR imaging of symptomatic and asymptomatic middle cerebral artery atherosclerotic stenosis. Atherosclerosis 2010;212:507-11 CrossRef Medline

21. Ryu CW, Jahng GH, Kim EJ, et al. High resolution wall and lumen MRI of the middle cerebral arteries at 3 Tesla. Cerebrovasc Dis 2009; 27:433-42 CrossRef Medline

22. Li ML, Xu WH, Song L, et al. Atherosclerosis of middle cerebral artery: evaluation with high-resolution MR imaging at 3T. Atherosclerosis 2009;204:447-52 CrossRef Medline
23. Toussaint JF, LaMuraglia GM, Southern JF, et al. Magnetic resonance images lipid, fibrous, calcified, hemorrhagic, and thrombotic components of human atherosclerosis in vivo. Circulation 1996;94: 932-38 CrossRef Medline

24. Yuan C, Mitsumori LM, Ferguson MS, et al. In vivo accuracy of multispectral magnetic resonance imaging for identifying lipid-rich necrotic cores and intraplaque hemorrhage in advanced human carotid plaques. Circulation 2001;104:2051-56 CrossRef Medline

25. Wasserman BA, Smith WI, Trout HH 3rd, et al. Carotid artery atherosclerosis: in vivo morphologic characterization with gadolinium-enhanced double-oblique MR imaging initial results. Radiology 2002;223:566-73 CrossRef Medline

26. Yuan $\mathrm{C}$, Petty $\mathrm{C}$, O’Brien $\mathrm{KD}$, et al. In vitro and in situ magnetic resonance imaging signal features of atherosclerotic plaque-associated lipids. Arterioscler Thromb Vasc Biol 1997;17:1496-503 CrossRef Medline

27. Han JS, Mandell DM, Poublanc J, et al. BOLD-MRI cerebrovascular reactivity findings in cocaine-induced cerebral vasculitis. Nat Clin Pract Neurol 2008;4:628-32 CrossRef Medline

28. Cheng-Ching E, Jones S, Hui FK, et al. High-resolution MRI vessel wall imaging in varicella zoster virus vasculopathy. J Neurol Sci 2015;351:168-73 CrossRef Medline

29. Obusez EC, Hui F, Hajj-Ali RA, et al. High-resolution MRI vessel wall imaging: spatial and temporal patterns of reversible cerebral vasoconstriction syndrome and central nervous system vasculitis. AJNR Am J Neuroradiol 2014;35:1527-32 CrossRef Medline

30. Choe YH, Kim DK, Koh EM, et al. Takayasu arteritis: diagnosis with MR imaging and MR angiography in acute and chronic active stages. J Magn Reson Imaging 1999;10:751-57 Medline

31. Choe YH, Han BK, Koh EM, et al. Takayasu's arteritis: assessment of disease activity with contrast-enhanced MR imaging. AJR Am J Roentgenol 2000;175:505-11 CrossRef Medline

32. Mandell DM, Matouk CC, Farb RI, et al. Vessel wall MRI to differentiate between reversible cerebral vasoconstriction syndrome and central nervous system vasculitis: preliminary results. Stroke 2012; 43:860-62 CrossRef Medline

33. Mossa-Basha M, Hwang WD, De Havenon A, et al. Multicontrast high-resolution vessel wall magnetic resonance imaging and its value in differentiating intracranial vasculopathic processes. Stroke 2015;46:1567-73 CrossRef Medline

34. Findlay JM, Weir BK, Kanamaru K, et al. Arterial wall changes in cerebral vasospasm. Neurosurgery 1989;25:736-45; discussion 745-46 CrossRef Medline

35. Serdaru M, Chiras J, Cujas M, et al. Isolated benign cerebral vasculitis or migrainous vasospasm? J Neurol Neurosurg Psychiatry 1984; 47:73-76 CrossRef Medline

36. Hajj-Ali RA, Furlan A, Abou-Chebel A, et al. Benign angiopathy of the central nervous system: cohort of 16 patients with clinical course and long-term followup. Arthritis Rheum 2002;47:662-69 CrossRef Medline

37. Aoki S, Hayashi N, Abe O, et al. Radiation-induced arteritis: thickened wall with prominent enhancement on cranial MR images report of five cases and comparison with 18 cases of Moyamoya disease. Radiology 2002;223:683-88 CrossRef Medline

38. Kim YJ, Lee DH, Kwon JY, et al. High resolution MRI difference between Moyamoya disease and intracranial atherosclerosis. Eur J Neurol 2013;20:1311-18 CrossRef Medline

39. Kim SM, Ryu CW, Jahng GH, et al. Two different morphologies of chronic unilateral middle cerebral artery occlusion: evaluation using high-resolution MRI. J Neuroimaging 2014;24:460-66 CrossRef Medline

40. Takagi Y, Kikuta K, Nozaki K, et al. Histological features of middle cerebral arteries from patients treated for Moyamoya disease. $\mathrm{Neu}$ rol Med Chir (Tokyo) 2007;47:1-4 CrossRef Medline

41. Ryoo S, Cha J, Kim SJ, et al. High-resolution magnetic resonance wall imaging findings of Moyamoya disease. Stroke 2014;45: 2457-60 CrossRef Medline

AJNR Am J Neuroradiol 38:218-29 Feb 2017 www.ajnr.org 
42. Iwama T, Andoh T, Sakai N, et al. Dissecting and fusiform aneurysms of vertebro-basilar systems. MR imaging. Neuroradiology 1990;32:272-79 CrossRef Medline

43. Wang Y, Lou X, Li Y, et al. Imaging investigation of intracranial arterial dissecting aneurysms by using $3 \mathrm{~T}$ high-resolution MRI and DSA: from the interventional neuroradiologists' view. Acta Neurochir (Wien) 2014;156:515-25 CrossRef Medline

44. Habs M, Pfefferkorn T, Cyran CC, et al. Age determination of vessel wall hematoma in spontaneous cervical artery dissection: a multisequence 3T cardiovascular magnetic resonance study. J Cardiovasc Magn Reson 2011;13:76 CrossRef Medline

45. Kitanaka C, Tanaka J, Kuwahara M, et al. Magnetic resonance imaging study of intracranial vertebrobasilar artery dissections. Stroke 1994;25:571-75 CrossRef Medline

46. Hosoya T, Adachi M, Yamaguchi K, et al. Clinical and neuroradiological features of intracranial vertebrobasilar artery dissection. Stroke 1999;30:1083-90 CrossRef Medline

47. Kim TW, Choi HS, Koo J, et al. Intramural hematoma detection by susceptibility-weighted imaging in intracranial vertebral artery dissection. Cerebrovasc Dis 2013;36:292-98 CrossRef Medline

48. Ahn SS, Kim BM, Suh SH, et al. Spontaneous symptomatic intracranial vertebrobasilar dissection: initial and follow-up imaging findings. Radiology 2012;264:196-202 CrossRef Medline

49. Chung JW, Kim BJ, Sohn CH, et al. Branch atheromatous plaque: a major cause of lacunar infarction (high-resolution MRI study). Cerebrovasc Dis Extra 2012;2:36-44 CrossRef Medline

50. Yoon Y, Lee DH, Kang DW, et al. Single subcortical infarction and atherosclerotic plaques in the middle cerebral artery: high-resolution magnetic resonance imaging findings. Stroke 2013;44:2462-67 CrossRef Medline

51. Klein IF, Lavallée PC, Mazighi M, et al. Basilar artery atherosclerotic plaques in paramedian and lacunar pontine infarctions: a high-resolution MRI study. Stroke 2010;41:1405-09 CrossRef Medline

52. Xu WH, Li ML, Niu JW, et al. Intracranial artery atherosclerosis and lumen dilation in cerebral small-vessel diseases: a high-resolution MRI study. CNS Neurosci Ther 2014;20:364-67 CrossRef Medline

53. Watanabe $\mathrm{H}$, Yoshida $\mathrm{K}$, Akasaka $\mathrm{T}$, et al. Intravascular ultrasound assessment of plaque distribution in the ostium of the left anterior descending coronary artery. Am J Cardiol 1996;78:827-29 CrossRef Medline

54. Xu WH, Li ML, Gao S, et al. Plaque distribution of stenotic middle cerebral artery and its clinical relevance. Stroke 2011;42:2957-59 CrossRef Medline

55. Zhu XJ, Du B, Lou X, et al. Morphologic characteristics of atherosclerotic middle cerebral arteries on 3T high-resolution MRI. AJNR Am J Neuroradiol 2013;34:1717-22 CrossRef Medline

56. Huang B, Yang WQ, Liu XT, et al. Basilar artery atherosclerotic plaques distribution in symptomatic patients: a 3.0T high-resolution MRI study. Eur J Radiol 2013;82:e199-203 CrossRef Medline

57. Aliabadi D, Tilli FV, Bowers TR, et al. Incidence and angiographic predictors of side branch occlusion following high-pressure intracoronary stenting. Am J Cardiol 1997;80:994-97 CrossRef Medline

58. Jiang WJ, Yu W, Ma N, et al. High resolution MRI guided endovascular intervention of basilar artery disease. J Neurointerv Surg 2011; 3:375-78 CrossRef Medline

59. Chen XY, Wong KS, Lam WW, et al. Middle cerebral artery atherosclerosis: histological comparison between plaques associated with and not associated with infarct in a postmortem study. Cerebrovasc Dis 2008;25:74-80 Medline

60. Yang WQ, Huang B, Liu XT, et al. Reproducibility of high-resolution MRI for the middle cerebral artery plaque at 3T. Eur J Radiol 2014;83:e49-55 CrossRef Medline

61. Chung GH, Kwak HS, Hwang SB, et al. High resolution MR imaging in patients with symptomatic middle cerebral artery stenosis. Eur J Radiol 2012;81:4069-74 CrossRef Medline

62. Glagov S, Weisenberg E, Zarins CK, et al. Compensatory enlargement of human atherosclerotic coronary arteries. $N$ Engl J Med 1987;316:1371-75 CrossRef Medline
63. Burke AP, Kolodgie FD, Farb A, et al. Morphological predictors of arterial remodeling in coronary atherosclerosis. Circulation 2002; 105:297-303 CrossRef Medline

64. Pasterkamp G, Wensing PJ, Post MJ, et al. Paradoxical arterial wall shrinkage may contribute to luminal narrowing of human atherosclerotic femoral arteries. Circulation 1995;91:1444-49 CrossRef Medline

65. Shi MC, Wang SC, Zhou HW, et al. Compensatory remodeling in symptomatic middle cerebral artery atherosclerotic stenosis: a high-resolution MRI and microemboli monitoring study. Neurol Res 2012;34:153-58 CrossRef Medline

66. Xu WH, Li ML, Gao S, et al. Middle cerebral artery intraplaque hemorrhage: prevalence and clinical relevance. Ann Neurol 2012;71: 195-98 CrossRef Medline

67. Kerwin WS, Oikawa M, Yuan C, et al. MR imaging of adventitial vasa vasorum in carotid atherosclerosis. Magn Reson Med 2008;59: 507-14 CrossRef Medline

68. Yuan C, Kerwin WS, Ferguson MS, et al. Contrast-enhanced high resolution MRI for atherosclerotic carotid artery tissue characterization. J Magn Reson Imaging 2002;15:62-67 CrossRef Medline

69. Qiao Y, Etesami M, Astor BC, et al. Carotid plaque neovascularization and hemorrhage detected by MR imaging are associated with recent cerebrovascular ischemic events. AJNR Am J Neuroradiol 2012;33:755-60 CrossRef Medline

70. Vergouwen MD, Silver FL, Mandell DM, et al. Eccentric narrowing and enhancement of symptomatic middle cerebral artery stenoses in patients with recent ischemic stroke. Arch Neurol 2011;68:338-42 CrossRef Medline

71. Qiao Y, Zeiler SR, Mirbagheri S, et al. Intracranial plaque enhancement in patients with cerebrovascular events on high-spatial-resolution MR images. Radiology 2014;271:534-42 CrossRef Medline

72. Skarpathiotakis M, Mandell DM, Swartz RH, et al. Intracranial atherosclerotic plaque enhancement in patients with ischemic stroke. AJNR Am J Neuroradiol 2013;34:299-304 CrossRef Medline

73. Lou X, Ma N, Ma L, et al. Contrast-enhanced 3T high-resolution MR imaging in symptomatic atherosclerotic basilar artery stenosis. AJNR Am J Neuroradiol 2013;34:513-17 CrossRef Medline

74. Tso E, Flamm SD, White RD, et al. Takayasu arteritis: utility and limitations of magnetic resonance imaging in diagnosis and treatment. Arthritis Rheum 2002;46:1634-42 CrossRef Medline

75. Kerr GS, Hallahan CW, Giordano J, et al. Takayasu arteritis. Ann Intern Med 1994;120:919-29 CrossRef Medline

76. Hoffman GS. Takayasu arteritis: lessons from the American National Institutes of Health experience. Int J Cardiol 1996;54(suppl): S99-102 CrossRef Medline

77. Hauenstein C, Reinhard M, Geiger J, et al. Effects of early corticosteroid treatment on magnetic resonance imaging and ultrasonography findings in giant cell arteritis. Rheumatology 2012;51:1999-2003 CrossRef Medline

78. Bley TA, Wieben $\mathrm{O}$, Uhl M, et al. High-resolution MRI in giant cell arteritis: imaging of the wall of the superficial temporal artery. $A J R$ Am J Roentgenol 2005;184:283-87 CrossRef Medline

79. Park JK, Lee CS, Sim KB, et al. Imaging of the walls of saccular cerebral aneurysms with double inversion recovery black-blood sequence. J Magn Reson Imaging 2009;30:1179-83 CrossRef Medline

80. Kleinloog R, Korkmaz E, Zwanenburg JJ, et al. Visualization of the aneurysm wall: a 7.0-Tesla magnetic resonance imaging study. $\mathrm{Neu}$ rosurgery 2014;75:614-22; discussion 622 CrossRef Medline

81. Matouk CC, Mandell DM, Günel M, et al. Vessel wall magnetic resonance imaging identifies the site of rupture in patients with multiple intracranial aneurysms: proof of principle. Neurosurgery 2013; 72:492-96; discussion 496 CrossRef Medline

82. Edjlali M, Gentric JC, Régent-Rodriguez C, et al. Does aneurysmal wall enhancement on vessel wall MRI help to distinguish stable from unstable intracranial aneurysms? Stroke 2014;45:3704-06 CrossRef Medline

83. Coutinho JM, Sacho RH, Schaafsma JD, et al. High-resolution vessel wall magnetic resonance imaging in angiogram-negative non-per- 
imesencephalic subarachnoid hemorrhage. Clin Neuroradiol 2015 Nov 25. [Epub ahead of print] Medline

84. Kataoka K, Taneda M, Asai T, et al. Structural fragility and inflammatory response of ruptured cerebral aneurysms: a comparative study between ruptured and unruptured cerebral aneurysms. Stroke 1999;30:1396-401 CrossRef Medline

85. Frösen J, Piippo A, Paetau A, et al. Remodeling of saccular cerebral artery aneurysm wall is associated with rupture: histological analysis of 24 unruptured and 42 ruptured cases. Stroke 2004;35:2287-93 CrossRef Medline

86. Suzuki J, Ohara H. Clinicopathological study of cerebral aneurysms. Origin, rupture, repair, and growth. J Neurosurg 1978;48: 505-14 CrossRef Medline

87. Steinman DA, Antiga L, Wasserman BA. Overestimation of cerebral aneurysm wall thickness by black blood MRI? J Magn Reson Imaging 2010;31:766 CrossRef Medline

88. Hui FK, Zhu X, Jones SE, et al. Early experience in high-resolution
MRI for large vessel occlusions. J Neurointerv Surg 2015;7:509-16 CrossRef Medline

89. Aydin F. Do human intracranial arteries lack vasa vasorum? A comparative immunohistochemical study of intracranial and systemic arteries. Acta Neuropathol 1998;96:22-28 CrossRef Medline

90. Takaba M, Endo S, Kurimoto M, et al. Vasa vasorum of the intracranial arteries. Acta Neurochir (Wien) 1998;140:411-16 CrossRef Medline

91. Portanova A, Hakakian N, Mikulis DJ, et al. Intracranial vasa vasorum: insights and implications for imaging. Radiology 2013; 267:667-79 CrossRef Medline

92. Aoki S, Shirouzu I, Sasaki Y, et al. Enhancement of the intracranial arterial wall at MR imaging: relationship to cerebral atherosclerosis. Radiology 1995;194:477-81 CrossRef Medline

93. Power S, Matouk C, Casaubon LK, et al. Vessel wall magnetic resonance imaging in acute ischemic stroke: effects of embolism and mechanical thrombectomy on the arterial wall. Stroke 2014;45: 2330-34 CrossRef Medline 